\title{
Dynamics of Terminal Arbor Formation and Target Approach of Retinotectal Axons in Living Zebrafish Embryos: A Time-Lapse Study of Single Axons
}

\author{
Rolf J. Kaethner and Claudia A. O. Stuermer \\ Faculty of Biology, University of Konstanz, D-7750 Konstanz, Germany
}

In a variety of species, developing retinal axons branch initially more widely in their visual target centers and only gradually restrict their terminal arbors to smaller and defined territories. Retinotectal axons in fish, however, appeared to grow in a directed manner and to arborize only at their retinotopic target sites. To visualize the dynamics of retinal axon growth and arbor formation in fish, time-lapse recordings were made of individual retinal ganglion cell axons in the tectum in live zebrafish embryos.

Axons were labeled with the fluorescent carbocyanine dyes Dil or DiO inserted as crystals into defined regions of the retina, viewed with $40 \times$ and $100 \times$ objectives with an SIT camera, and recorded, with exposure times of $200 \mathrm{msec}$ at 30 or $60 \mathrm{sec}$ intervals, over time periods of up to $13 \mathrm{hr}$. (1) Growth cones advanced rapidly, but the advance was punctuated by periods of rest. During the rest periods, the growth cones broadened and developed filopodia, but during extension they were more streamlined. (2) Growth cones traveled unerringly into the direction of their retinotopic targets without branching en route. At their target and only there, the axons began to form terminal arborizations, a process that involved the emission and retraction of numerous short side branches. The area that was permanently occupied or touched by transient branches of the terminal arbor-"the exploration field" - was small and almost circular and covered not more than $\mathbf{5 . 3} \%$ of the entire tectal surface area, but represented up to six times the size of the arbor at any one time.

These findings are consistent with the idea that retinal axons are guided to their retinotopic target sites by sets of positional markers, with a graded distribution over the axes of the tectum.

When neurons differentiate, they extend axons often into distant parts of the brain. Once at their target, the axons develop complex terminal arborizations and contacts with other neurons leading ultimately to the establishment of highly ordered nerve cell connections.

The rules that govern target choice and the formation of specific contacts are not entirely understood. However, several lines

\footnotetext{
Received Aug. 27, 1991; revised Mar. 26, 1992; accepted Mar. 31, 1992.

This work was supported by the Deutsche Forschungsgemeinschaft, Stu 112 and SFB 156, C6, to C.A.O.S. We thank Jost Vielmetter and Martin Bastmeyer, who were involved in establishing the time-lapse videomicroscopy setup, and Carol A. Mason and A. Gierer for helpful comments on the manuscript.

Correspondence should be addressed to Claudia A. O. Stuermer at the above address.
}

Copyright (C) 1992 Society for Neuroscience $0270-6474 / 92 / 123257-15 \$ 05.00 / 0$ of evidence suggest that the target provides cues that guide the axons and mediate axon target recognition (Sperry, 1963; Gierer, 1987) and trigger the initiation of axon arborizations and the formation of synapses between axons and their target cells. A conventional approach to unravel the mechanisms that lead to specific nerve cell interconnections is to dye label a small group of axons in a series of animals at progressive ages and to deduce the development of axon target innervation from a series of snapshots. More recently, however, it has become possible to observe individual axons during their growth in live animals or in semi-intact preparations (Harris et al., 1987; Rich and Lichtman, 1989; Godement and Mason, 1990; Herrera et al., 1990; O’Rourke and Fraser, 1990; Sretavan, 1990; Wigston, 1990). This method, the visualization of live axons, has been employed in the present investigation to explore the dynamics of retinotectal axon growth and arbor formation in the tectum opticum of fish embryos.

The retinotectal system has been used extensively for studies on axon target recognition, and striking differences between species were noted in the development of this projection. All vertebrates analyzed so far exhibit a precisely organized retinotopic projection of the retinal axons onto the tectum as adults (Gaze, 1970; Crossland et al., 1975; Stone et al., 1984). However, when retinal axons in rats or birds were stained and viewed in fixed brains at different stages of development, a number of axons were seen with arbors or side branches over nonretinotopic (i.e., ectopic) regions of the tectum (O'Rourke and Fraser, 1986, 1990; Nakamura and O'Leary, 1989; Simon and O'Leary, 1990). Those ectopic side branches had disappeared in mature animals. Widespread ramifications were also found to be typical for regenerating retinotectal axons in amphibians (Fujisawa et al., 1982) and goldfish (Schmidt ct al., 1988; Stucrmer, 1988a,b). Morc recently, the formation and dynamic rearrangements of arbors were shown directly in living embryos of Xenopus with videomicroscopy (O'Rourke and Fraser, 1986, 1990; Harris et al., 1987). Xenopus axons from temporal or nasal retina did not grow to their correct target area as simple axons and then elaborate an arbor, but grew into the tectal neuropil from the rostral edge and ramified to form arbors in overlapping areas (O'Rourke and Fraser, 1990). Only gradually with the growth of the tectum predominantly at its caudal end did nasal arbors sprout processes into the new territory and remove branches from the rostral tectum. This process lead over $4 \mathrm{~d}$ to the selective occupance of rostral tectum by temporal axons and caudal tectum by nasal axons.

In fish embryos, specifically in zebrafish, the first axons reach and arborize over their target sites within $24 \mathrm{hr}$ after ingrowth into the tectum (Stuermer, 1988c; Stuermer et al., 1990). An- 
alyzed in fixed brains of animals at different stages, these axons were seen to run in straight routes to their target sites and had small terminal arbors exclusively confined to their retinotopically appropriate domains (Stuermer, 1988c; Stuermer and Raymond, 1989; Stuermer et al., 1990).

These studies suggested that fish retinal axons are from the time of ingrowth into the tectum highly selective in their target approach and choice. Is it that the wide-range refinement of visual projections in embryonic development in other vertebrate species or during optic nerve regeneration in fish (Schmidt et al., 1988; Stuermer, 1988a,b; Xenopus: O'Rourke and Fraser, 1986, 1990; chick: Nakamura and O'Leary, 1989; rat: Simon and O'Leary, 1990; cat: Sretavan and Shatz, 1986) is not required in zebrafish embryos?

Using time-lapse videomicroscopy, we have in this report monitored the growth of individual axons in the tectum of living zebrafish embryos. This technique allowed us to visualize axon growth in vivo continuously over hours, which is usually only possible in tissue culture. The process of terminal arbor formation turned out to be a highly dynamic event involving the extension and retraction of side branches in a rapid sequence. Branching, however, was indeed clearly restricted to a retinotopically appropriate and almost circular area, covering no more than $5.3 \%$ of the tectal surface. The observation of these living axons also highlighted previously unseen characteristics of growth cone advancement and the relation to growth cone shape. Individual growth cones alter their shape periodically; they acquire a streamlined form and elongate rapidly, and then pause and develop distinct veils and filopodia as if they explored their environment. Axon growth and arbor formation in zebrafish embryos proceed in fact as predicted by Gierer (1987) under the premise that axons recognize and respond to positional markers distributed over the tectum in gradients.

Parts of these results were published as an abstract (Kaethner and Stuermer, 1990).

\section{Materials and Methods}

Observations of growing retinotectal axons were performed in the mutant zebrafish embryo strain goll/goll. Zebrafish carrying the mutation were kindly provided by Charles Kimmel, University of Oregon, and propagated over 3 years in our breeding colony. In contrast to wildtype embryos, the mutant has transparent melanophores. The melanophores are visible (as in Fig. 5, frames 7-16) but carry much fewer black pigment granules; thus, we were able to view labeled axons through the skin and unopened skull. Adult fish and embryos were kept on 14 $\mathrm{hr}: 10 \mathrm{hr}$ light/dark cycles at $28^{\circ} \mathrm{C}$. Eggs were collected and staged within 1-2 $\mathrm{hr}$ after spontaneous spawning. Zebrafish hatch at about $72 \mathrm{hr}$ postfertilization (PF) and reach adulthood by 3-4 months. For cxperimental manipulations prior to hatching, embryos were removed from their egg cases with pointed forceps and kept in small Petri dishes in water.

Application of DiI or DiO. Dye applications were performed in embryos of 33-36 hr, 55-60 hr, and $84 \mathrm{hr}$ PF. Embryos were anesthetized with $0.03 \%$ tricaine methane sulfonate (MS 222, Sigma) in water and placed on moist tissue. The eye was opened with a pointed needle, and a small crystal (roughly $20-100 \mu \mathrm{m}$ diameter) of DiI $\left(1,1^{\prime}\right.$-dioctadecyl$3,3,3^{\prime}, 3^{\prime}$-tetramethylindocarbocyanine perchlorate; Serva) or $\mathrm{DiO}\left(N, N^{\prime}\right.$ dioctadecyloxacarbocyanine 4-toluene sulfonate; Serva) was inserted into the nasal or temporal region of retina between the optic disk and the retinal periphery, in either the dorsal or ventral retinal half. DiO was finally preferred over DiI since growing axons appeared to survive longer during the illumination with fluorescent light (see below).

In vivo time-lapse video microscopy. After dye application (16-24 hr), the embryo was reanesthetized and placed on a coverslip in a position that allowed a dorsolateral view onto the optic tectum contralateral to the labeled eye. The water surrounding the embryo was sucked off and the embryo was covered with oxygen-diffusible Voltalef oil (Atochem).
A silicon ring was set around the embryo to prevent lateral drifting. Only embryos with normal blood flow and a single or a few labeled axons in their tecta were selected for in vivo time-lapse observations.

The microscope (Zeiss Axioplan) was equipped with Nomarski differential interference contrast (DIC) optics, epifluorescence filter sets for fluorescein isothiocyanate and tetramethyl-rhodamine isothiocyanate, $20 \times, 40 \times$ and $100 \times$ oil-immersion lenses, an infrared filter, and a 100 W xenon lamp. An SIT camera was mounted to the microscope. Continuous illumination of DiI- or DiO-labclcd axons with fluorescent light over longer time periods was seen to photodamage the axons and to cause them to degenerate. Growth cones ceased to grow or collapsed, and arbors stopped to extend processes and soon thereafter acquired a beaded appearance. To reduce the duration of light exposure, a shutter was inserted into the light path, which opened the light path in intervals of $30 \mathrm{sec}$ or $60 \mathrm{sec}$ for only $200 \mathrm{msec}$. Within these $200 \mathrm{msec}$, three frames were shot, averaged, and enhanced by a digital image processor (Hamamatsu). The processed frames were received by a videorecorder (Sony) connected to a time-lapse system (EOS). Time-lapse recordings of axons were terminated when the blood flow in the brain had stopped or when the axons showed the first signs of abnormalities presumably originating from light exposure.

Boundaries of the tectum and adjacent areas of the brain were visible with Nomarski optics and with fluorescence light through $20 \times$ lenses (Fig. 1), and the tectal position of the axons selected for time-lapse recording was determined. Under fluorescent light, the tectal neuropil appears lighter than its surround (Stuermer, 1988c). As described previously (Stuermer, 1988c), the tectum consists of two regions, the tectal neuropil, which is or will be occupied by the retinal axons, and the zone consisting of elongated cells surrounding the neuropil laterally and caudally.

Sizes of neuropil and terminal arbors. To determine the entire extent of individual axonal arbors, they were monitored in different focal depths, stepwise at the beginning and in real time at the end of a recording session. Single images were photographed or drawn from the screen of a monitor.

Drawings were made from the tectal neuropil at the end of a recording period. The surface area of the neuropil, the area covered by an arbor, and the arbor's "exploration field" (i.e., the entire area into which the arbor had extended processes over time) was approximated in the following way. Grids of equal-sized squares were laid over the neuropil and arbors, and all "occupied" squares were counted and added. The squares were $1.3 \mu \mathrm{m} \times 1.3 \mu \mathrm{m}$ for size determination of the arbors and their exploration fields, and $3.3 \mu \mathrm{m} \times 3.3 \mu \mathrm{m}$ for the neuropil. The area value of the arbors and their exploration fields was set into relation to the neuropil area

For a comparison with arbor sizes determined in an earlier study (Stuermer, 1988c), the long and short axes of the arbors were measured at the beginning and end of a recording session.

\section{Results}

Using intraretinal applications of $\mathrm{DiI}$ and $\mathrm{DiO}$, an earlier study (Stuermer, 1988c) has demonstrated the path of retinotectal axons in wild-type zebrafish after fixing their brains. These axons, whether from nasal or temporal pole, were seen to run in the direction of their retinotopic target sites, where they formed terminal arbors of defined sizes. These axons did not appear to branch en route. Only a very few axons occasionally exhibited an individual short and thin side branch at distances away from the terminal arbor proper. Before the axons had arrived at their retinotopic target sites, nasal and temporal axons were transiently coextensive over the rostral tectal half, because they arrive and move over the tectum as a front. Neither nasal nor temporal axons were seen to arborize until they had reached their retinotopic target sites (Stuermer, 1988c); that is, temporal axons remained in the rostral tectal half to develop their terminal arbors, and nasal axons headed into the caudal tectum and arborized selectively over their retinotopically appropriate target territory. Nasal and temporal axons from the dorsal and ventral retinal halves occupied the retinotopically corresponding ventral and dorsal tectal halves, respectively. The retinotopic 
organization of the developing retinotectal projection was confirmed for embryos of the goll/goll mutant strain used in the present study. Therefore, for axons that are still growing, the location of their prospective target sites is defined as tectal areas correlating retinotopically to the site of dye crystal application in the retina.

The observations of the growing axons in live embryos revealed a striking difference in axon growth bchavior prior to and after their arrival at the retinotopic target sites. Prior to target arrival, each axon was led by a single growth cone that advanced through the tectum directly toward its retinotopic destination. The target-oriented path of a ventronasal axon is shown by the drawing in Figure 1, and its growth mode is illustrated in Figure 3. Time-lapse recordings had begun when the axon had reached central areas of the tectal neuropil. The axon traveled straight on into and through the caudal tectal half without branching en route. Four individual temporal (in four fish) and three individual nasal axons (in one fish) were followed during their growth through the rostral tectum in embryos 78$81 \mathrm{hr}$ old. Four further nasal axons (in three fish) were observed individually as they passed from the rostral into the caudal tectal half in embryos 79-81 hr old. Neither nasal nor temporal zebrafish retinal axons arborized over nonretinotopic tectal areas. Nasal and temporal axons also showed no significant difference in velocity or mode of growth described in more detail in the next paragraph. One temporal axon (whose arbor development is illustrated in Figs. 3, 5,6) was seen to carry a short side branch $80 \mu \mathrm{m}$ proximal to its terminal arbor (see Fig. $6 d$ ). We missed the formation of this specific branch, but followed the development of similar transient branches on several axons as in Figure 2 and in other cases. Such branches arose from episodes during which the growth cone briefly deviated from its targetdirected route. With the retraction of lamellipodia and filopodia from this deviant route, a thin branch remained while a new growth cone developed and resumed the original target-oriented growth direction. As in earlier studies (Stuermer, 1984, 1988c; Stuermer et al., 1990), these branches were not included in the size determination of the terminal arbors (see the last section of Results).

These observations on the growth behavior of live axons arc consistent with the conclusion derived from analyzing the morphology of axons in fixed brains of embryos of various ages. Thus, unlike axons in the amphibian tectum, zebrafish axons rarely branch while they advance and pass through nonretinotopic tectal domains. In accordance with this conclusion was the behavior of small populations of nasal axons observed in the tectum of 53- and 56-hr-old embryos. At these early stages, the axons that are labeled and monitored must be among the first ones that are progressing into the caudal tectum (Stuermer, $1988 \mathrm{c}$ ). Figure $2 a$ shows the morphology of a group of three or four nasal axons in the rostal tectum of a 56-hr-old embryo with growth cones at midtectal levels. None of these axons carried side branches over the rostral tectum. The progression of the large bifurcated growth cone (which may be a joined cone from two axons) was recorded over $9 \mathrm{hr}$, and it acquired an appearance as shown in Figure $2 b$. The axon did not emit side branches. The small branch seen in Figure $2 b$ was the remnant of the left arm of the bifurcated growth cones in Figure $2 a$. Thus, the emission of side branches prior to arrival at retinotopic target site was a rare event.

The analysis of further populations of growing axons in embryos of $53 \mathrm{hr} \mathrm{PF}$ and the later developmental ages gave the

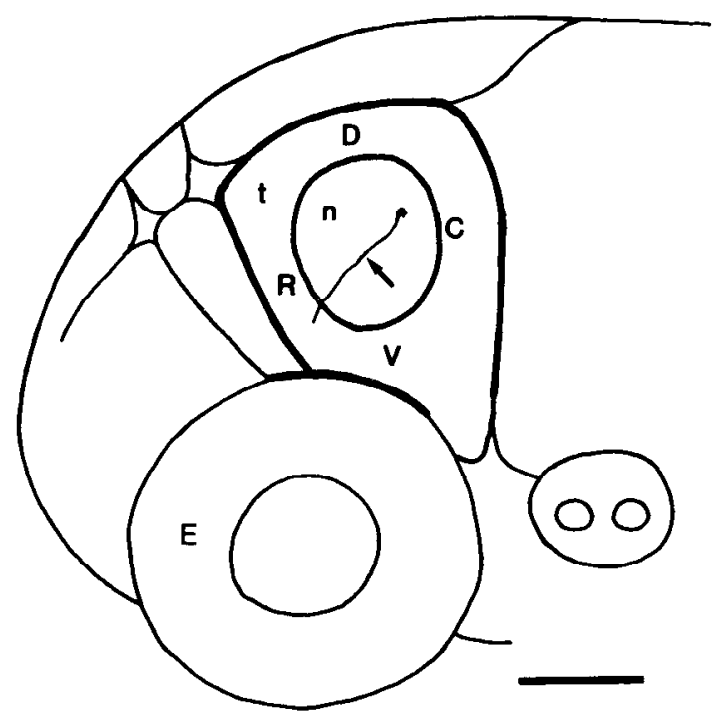

Figure 1. Head of a zebrafish embryo (79 hr PF) and outlines of its brain areas as visible through the unopened skull. The left tectum is cncirclcd by a heavy line containing the tcetal ncuropil. The path of a ventronasal axon in the left tectum (labeled with $\mathrm{DiO}$ ) from the right eye is shown by the thin line. Time-lapse recordings were made as the axon reached central tectum (arrow) and advanced to its destination in the caudal tectum (compare Fig. 3). This axon grew without extending side branches directly toward its retinotopic home. $C$, caudal; $D$, dorsal; $E$, eye; $R$, rostral; $V$, ventral; $n$, neuropil; $t$, tectum. Scale bar, $100 \mu \mathrm{m}$.

same result. Except for an occasional short side branch as on the axons in Figure $2 b$ (see also Fig. $6 d$ ), axons had neither branched over the rostral tectum nor produced branches during their path through the caudal tectum. However, once the axons had arrived at their retinotopic target territories in the posterior end of the caudal tectal half, they began to arborize in the mode further described below.

Thus, this target-directed aspect of axonal growth previously observed in fixed brains (Stuermer, 1988c) was confirmed by the observations on live axons. The mode in which the growth concs altercd their morphologies and the mode in which the axons developed their terminal arbors, however, were not expected from analyses on fixed preparations and were only appreciated from live observations.

Saltatory growth. Consistent with the description of growth cone morphologies in target organs of other species (e.g., Scalia and Matsumoto, 1985; Bovolenta and Mason, 1987; Stuermer, 1988b), the retinal axons' growth cones occurred in various shapes. They were tipped with either a broad growth cone with lamellipodia and numerous filopodia (defined as growth cone morphology A in Table 1) or with a spade-like growth cone with a long, forward-directed filopodium-like process (defined as growth cone morphology B in Table 1). The time-lapse recordings revealed that individual growth cones transitted sequentially between one or the other form. The sequential alterations in shape are exemplified in Figure 3 by an individual growth conc over $1 \mathrm{hr} 52 \mathrm{~min}$ and over roughly $30 \mu \mathrm{m}$ of its rostrocaudal path, observed through a $100 \times$ lens, $200 \mathrm{msec}$ exposure time, every $60 \mathrm{sec}$. As it progressed, the formerly spiky growth cone extended a filopodium-like process (Fig. 3, 0:23-0:44), and then became streamlined and elongated over $20 \mu \mathrm{m}$ in a forward direction. Thereafter, it changed its (spade-like) shape and widened with the formation of lamellipodia well behind the leading 
(a)

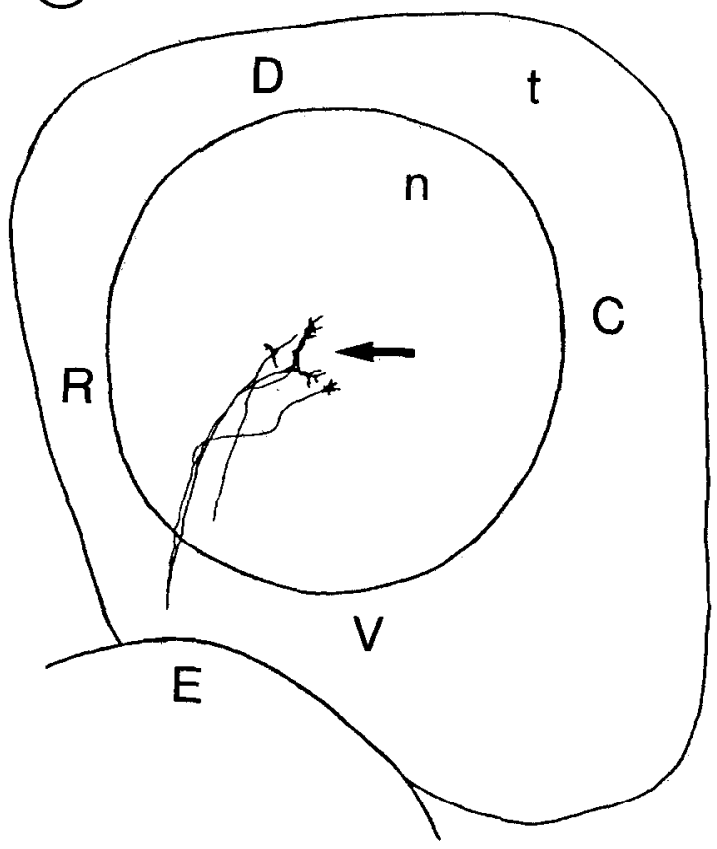

(b)

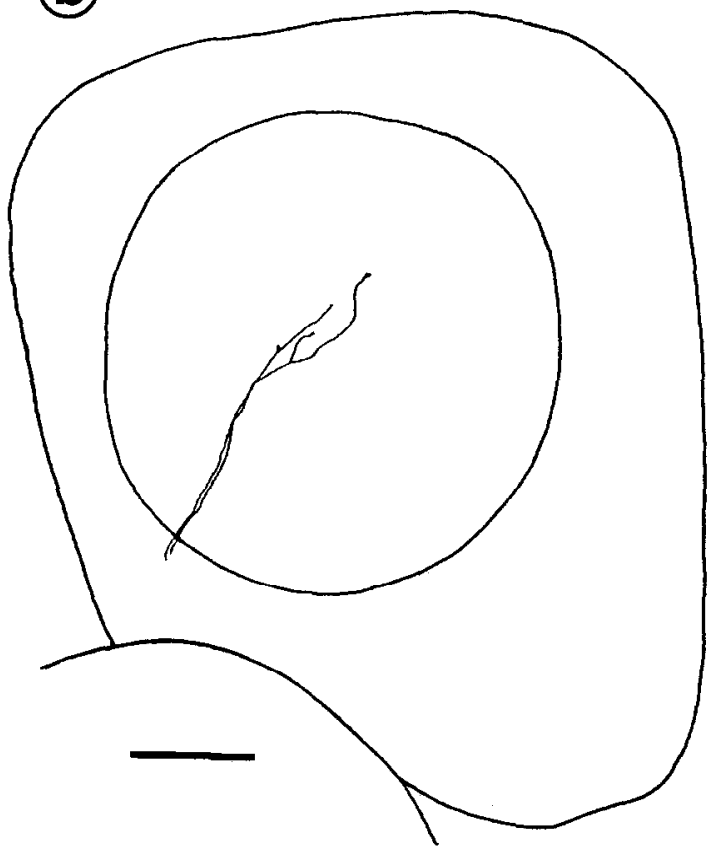

Figure 2. A group of axons from the ventronasal retina in the tectum of an embryo at $53 \mathrm{hr}$ PF (a) and at $62 \mathrm{hr}$ PF (b). a, At $55 \mathrm{hr}$ PF, the growth cones had reached midtectal regions. On their paths through the rostral tectal half, the nasal axons did not emit any side branches. $b$, The large growth cone (arrow in $a$ ) was monitored continuously over 9 hr, during which it moved farther into the caudal tectum. The short process seen on the axon at midtectal levels is the remnant of the lefthand arm of the growth cone in $a$. Abbreviations are as in Figure 1. Scale bar, $50 \mu \mathrm{m}$.

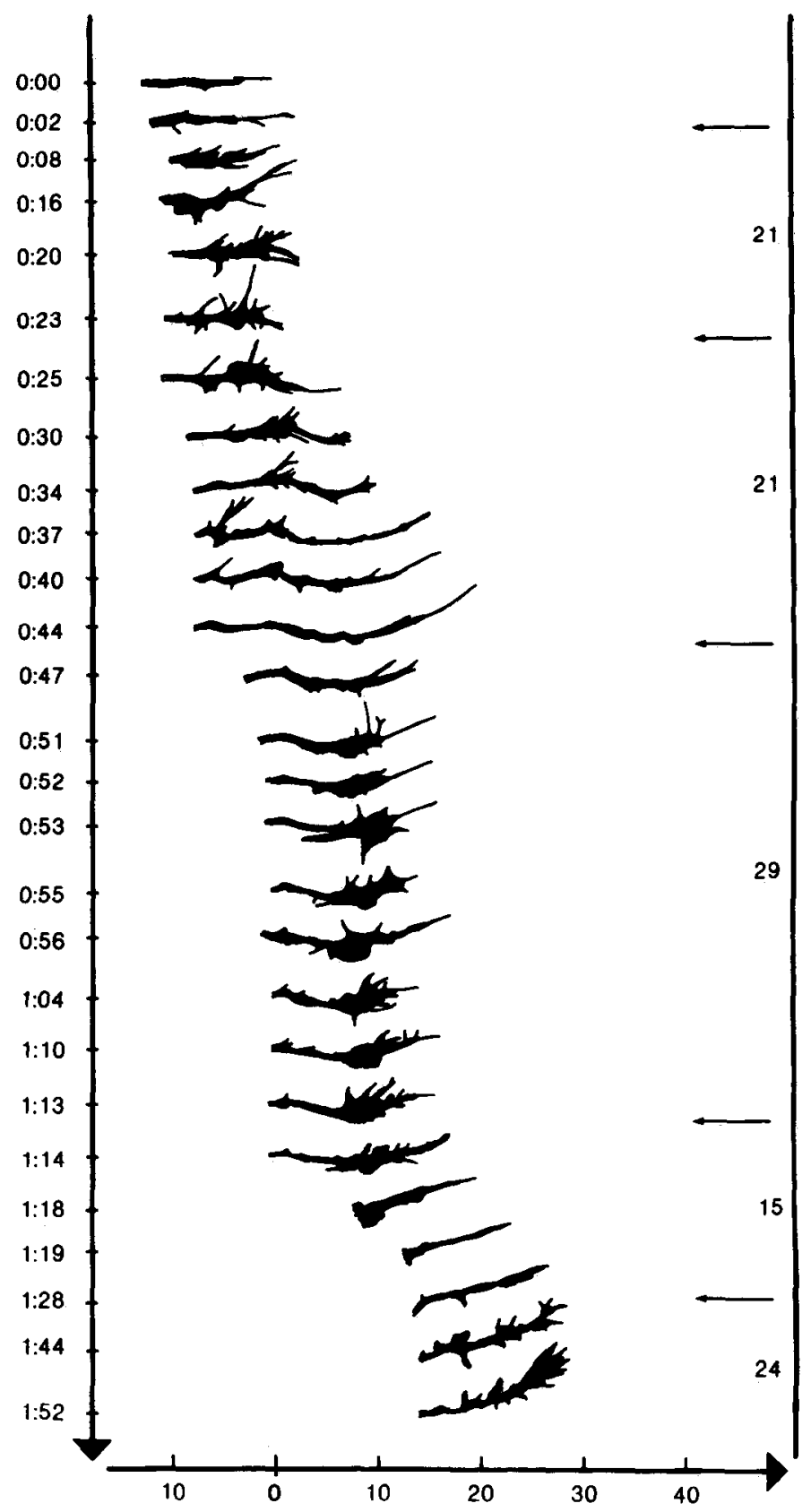

Figure 3. Typical morphological changes of growth concs during thcir progression through the tectum exemplified by a ventronasal axon (same axon as in Fig. 1). To the left, time in hours and minutes; to the right, time intervals in minutes (marked by arrows) between growth cone stretching and rapid advancement, and growth cone enlargement and pausing. The distances covered over time are indicated on the abscissa in microns.

tip. The reformation of lamellipodia occurred without significant growth cone advancement (Fig. 3, 0:47-1:13). Then followed a new phase of elongation (Fig. 3, 1:14-1:28) along with the acquisition of a streamlined growth cone form, and the cycle started again. This behavior was typical for almost all growth cones observed with sufficient resolution $(N=9)$. The measurements on the time the growth cone spent in a more widened form, the time for the extension of a filopodium that the growth cone followed, and the distances covered by the growth cone and its filopodium, respectively, are given in Table 1. As is evident from Table 1, growth cones cover no or very small 
(a)

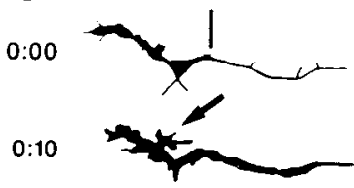

$0: 19$

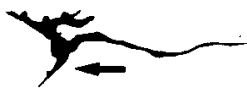

$0: 29$

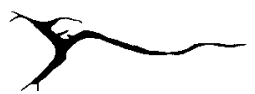

$0: 40$

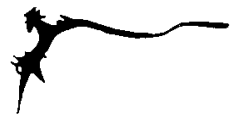

$0: 54$

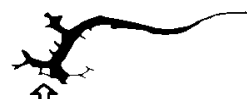

1:17

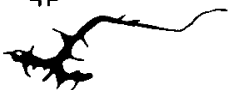

$1: 27$

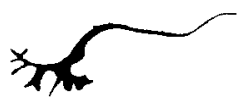

$1: 39$

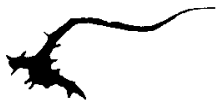

$1: 52$

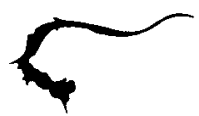

2:06

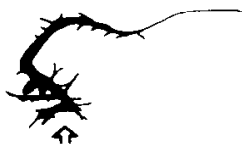

2:20

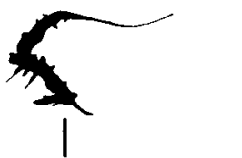

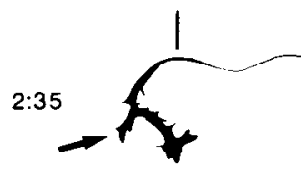

$3: 00$

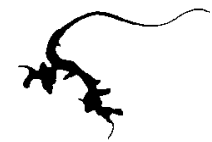

$3: 14$

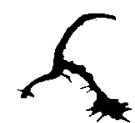

$3: 25$

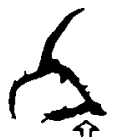

$3: 48$

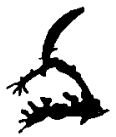

$3: 59$

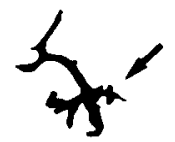

$4: 10$

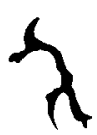

$4: 38$

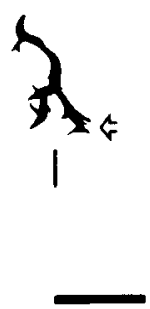

$4: 53$

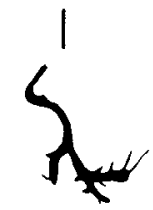

$5: 13$

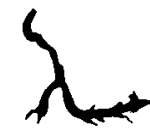

$5: 59$

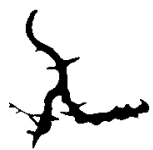

$6: 32$
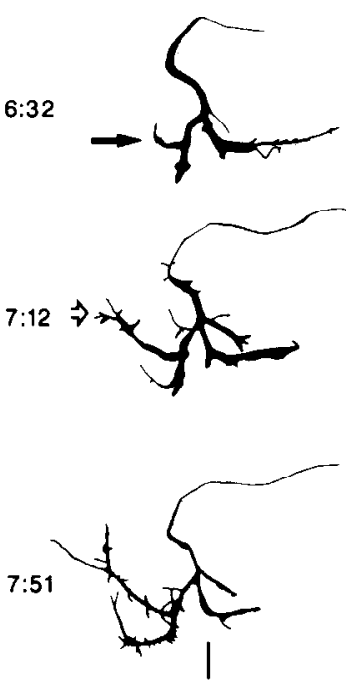

(b)

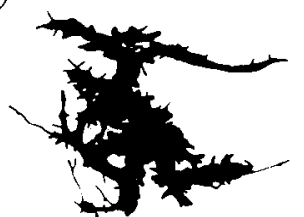

Figure 4. a, A growth cone from a ventrotemporal axon developing its terminal arbor over a small field in the dorsorostral tectum. The time over which the time-lapse recordings are made is indicated to the left in hours and minutes. Solid arrows point to new branches formed by back-branching, and open arrows, to locations where branches arose from a division of growth cone-like features. The vertical bars on the top and bottom of each column mark a stable imaginary line around which the arbor develops. $b$, The exploration field of the developing arbor in $a$. Scale bar, $20 \mu \mathrm{m}$. distances while they exhibit a widened morphology. The time they spend in this state, however, is on average much longer (between 5 and $92 \mathrm{~min}$ ) than the time during which they exhibit a streamlined morphology. Streamlined growth cones, on the other hand, progress rapidly, covering distances between 4 and $20 \mu \mathrm{m}$ in $1-20 \mathrm{~min}$.

Only one of the nine growth cones analyzed so far showed one cycle in which ruffling lamellipodia surrounded the forwarddirected filopodium in a tongue-like formation and the lamellipodia and the filopodium advanced simultaneously and smoothly. Thus, a typical but not obligatory mode in which axons progress through the tectum is in a kind of "stop-andgo" mode, in which rapid advancement of $112.2 \mu \mathrm{m} / \mathrm{hr}( \pm 84.3$ $\mu \mathrm{m} / \mathrm{hr} \mathrm{SD}$, mean velocity over 41 cycles of nine growth cones) by elongation alternates with phases in which growth cones pause and enlarge. The result is an average velocity of growth cone progression in the range of $6.4-17.3 \mu \mathrm{m} / \mathrm{hr}$ with a mean of $10.7 \mu \mathrm{m} / \mathrm{hr}(\mathrm{SD}, \pm 3.1 \mu \mathrm{m} / \mathrm{hr} ; n=15)$. These values are similar to those estimated from fixed embryos (Stuermer, 1988c).

In the tectum, axons advanced more slowly than in the tract. Six individual axons were monitored in the tract close to their entrance into the tectum (from $1 \mathrm{hr} 35 \mathrm{~min}$ to $3 \mathrm{hr}$ ) and found to have an average growth velocity of $17.8 \mu \mathrm{m} / \mathrm{hr}(\mathrm{SD}, \pm 4.4$ $\mu \mathrm{m} / \mathrm{hr}$ ) with a range of $12.8-34.5 \mu \mathrm{m} / \mathrm{hr}$.

Dynamics of arbor formation. When axons arrived at their target area in the tectum, their growth behavior changed dramatically in that they ceased to advance and began to develop their terminal arbors. Arbor development turned out to be a highly dynamic event that involved in parallel the extension as well as retractions of branches. Figure 4 exemplifies the morphological changes of a ventrotemporal axon (in a $76 \mathrm{hr} \mathrm{PF}$ embryo) arriving at its target site in the dorsorostral tectum. Prior to its arrival, this axon was observed to advance with a single growth cone toward its target. It was viewed and recorded 
Table 1. Cycles of growth cone advancement

\begin{tabular}{|c|c|c|c|c|c|c|c|c|c|c|c|c|c|}
\hline \multirow[b]{3}{*}{$\mathrm{C}^{b}$} & \multirow[b]{3}{*}{$\mathbf{M}^{c}$} & \multicolumn{12}{|c|}{ Growth cones ${ }^{a}$} \\
\hline & & \multicolumn{3}{|l|}{1} & \multicolumn{3}{|l|}{2} & \multicolumn{3}{|l|}{3} & \multicolumn{3}{|l|}{4} \\
\hline & & $\begin{array}{l}t \\
(\mathrm{~min})\end{array}$ & $\begin{array}{l}d \\
(\mu \mathrm{m})\end{array}$ & $\begin{array}{l}\nu(\mu \mathrm{m} / \\
\mathrm{hr})\end{array}$ & $\begin{array}{l}t \\
(\mathrm{~min})\end{array}$ & $\begin{array}{l}d \\
(\mu \mathrm{m})\end{array}$ & $\begin{array}{l}v(\mu \mathrm{m} / \\
\mathrm{hr})\end{array}$ & $\begin{array}{l}t \\
(\mathrm{~min})\end{array}$ & $\begin{array}{l}d \\
(\mu \mathrm{m})\end{array}$ & $\begin{array}{l}\nu(\mu \mathrm{m} / \\
\mathrm{hr})\end{array}$ & $\begin{array}{l}t \\
\text { (min) }\end{array}$ & $\begin{array}{l}d \\
(\mu \mathrm{m})\end{array}$ & $\begin{array}{l}\nu(\mu \mathrm{m} / \\
\mathrm{hr})\end{array}$ \\
\hline \multirow[t]{2}{*}{1} & A & & & & 5 & 5 & 60 & 16.5 & 14 & 50 & 3 & 8 & 160 \\
\hline & B & 50 & - & - & 25 & - & - & 49 & - & - & 13 & - & - \\
\hline \multirow[t]{2}{*}{2} & A & 20 & 20 & 60 & 11 & 20 & 109 & 7 & 19 & 161 & 4 & 5 & 80 \\
\hline & $\mathrm{B}$ & 40 & - & - & 30 & - & - & 18 & - & - & 15.5 & - & - \\
\hline \multirow[t]{2}{*}{3} & A & 10 & 7 & 42 & 11 & 6 & 33 & 5 & 13 & 150 & 3.5 & 8 & 142 \\
\hline & B & 10 & - & - & 28 & - & - & 69 & 4 & 4 & 5 & - & - \\
\hline \multirow[t]{2}{*}{4} & $\mathrm{~A}$ & 20 & 17 & 51 & 11 & 12 & 65 & 7 & 6 & 54 & 6 & 7 & 67 \\
\hline & B & 50 & - & - & 29 & - & - & 27.5 & - & - & 16 & - & - \\
\hline \multirow[t]{2}{*}{5} & A & & & & 20 & 5 & 15 & 10 & 7 & 40 & 11 & 13 & 69 \\
\hline & B & & & & 40 & - & - & 26 & - & - & 27.5 & - & - \\
\hline \multirow[t]{2}{*}{6} & A & & & & & & & 11.5 & 11 & 57 & 3 & 9 & 174 \\
\hline & B & & & & & & & & & & 26.5 & - & - \\
\hline \multirow[t]{2}{*}{7} & A & & & & & & & & & & 10 & 8 & 48 \\
\hline & B & & & & & & & & & & & & \\
\hline \multirow[t]{2}{*}{8} & A & & & & & & & & & & & & \\
\hline & B & & & & & & & & & & & & \\
\hline \multirow[t]{2}{*}{9} & A & & & & & & & & & & & & \\
\hline & B & & & & & & & & & & & & \\
\hline \multirow[t]{2}{*}{10} & A & & & & & & & & & & & & \\
\hline & B & & & & & & & & & & & & \\
\hline \multirow[t]{2}{*}{11} & A & & & & & & & & & & & & \\
\hline & B & & & & & & & & & & & & \\
\hline \multirow[t]{2}{*}{12} & A & & & & & & & & & & & & \\
\hline & $\mathrm{B}$ & & & & & & & & & & & & \\
\hline
\end{tabular}

${ }^{a} t$, the time the growth cone spends in states A and B, respectively (see below); $d$, the distances that it covers in states A and B, respectively; $v$, velocity; - , the growth cone did not cover measurable distances.

${ }^{b}$ The number of cycles (C) over which the growth cones were observed (1, 2, 3 etc.).

through the $40 \times$ lens with $200 \mathrm{msec}$ exposure every $30 \mathrm{sec}$. The axon retained its growth cone or growth cone-like feature at its tip, but no longer advanced into its original direction. It first extended lamellipodia and short filopodia into various directions and then assembled its active and leading lamellipodia preferentially over a branch that was at a right angle to the original axon proper. Subsequent growth activities were concentrated over this curving branch until a second branch sprouted some microns distal to the curved process' tip. The second branch grew longer, but was then withdrawn. Meanwhile, the first branch continued to produce further extensions and retracted some of them. The axon finally (Fig. 4, at 4:53) carried two branches, which arose from a bifurcation of the leading growth cone (indicated at 3:25 in Fig. 4). The two branches elaborated, into opposite directions, additional branches with numerous thin filopodia and elongated them. The right-hand branch and its appendices, however, retracted a bit, while the left-hand branch became thinner and decorated with a growing number of secondary branches. This behavior of branch elaboration and retraction was typical for all arbors observed in this study (see below). We have chosen the term "exploratory" growth of terminal arbors to describe their behavior over their retinotopic home territory.

Further axons $(n=10)$ were recorded not at the very onset of arbor formation as in Figure 4, but when they had already produced their first branches and continued to elaborate their arbors. Without exception, these arbors developed and performed their exploratory growth over their retinotopic target areas. Of these arbors, six were from temporal retina and explored a small region of the rostral tectum, and four were from nasal retina and developed their arbors each over a small caudal tectal field.

A series of photographs (Fig. 4) illustrates one example of the typical growth behavior of arbors (although still pictures can hardly convey the dynamic changes in a satisfactory way). This arbor from a ventrotemporal axon (78 hr PF embryo) was in the dorsorostral tectum and was observed (through the $100 \times$ lens with $200 \mathrm{msec}$ exposure time at every $30 \mathrm{sec}$ ) over $13 \mathrm{hr}$ of its development without interruption. Upon start of the timelapse recordings, the small arbor had two main branches, 12 and $14 \mu \mathrm{m}$ long, and a shorter branch, emerging from a bifurcation point proximal to the origin of the two other branches (Fig. $6 a$ ). This branch was retracted, such that the final bifurcation point that persisted to the end of the observation time (Fig. 6b) was the point of origin of the two longer branches (Figs. 5 , frames $1-12 ; 6 a$ ). The two main branches carried large and spiky growth cone-like processes. Over the next $10 \mathrm{hr}$, the arbor changed its arborization pattern entirely. Branches emerged anywhere and at any given time and were pulled back in a similar unpredictable manner. The likelihood that further branches 


\begin{tabular}{|c|c|c|c|c|c|c|c|c|c|c|c|c|c|c|}
\hline \multicolumn{15}{|c|}{ Growth cones ${ }^{a}$} \\
\hline \multicolumn{3}{|l|}{5} & \multicolumn{3}{|l|}{6} & \multicolumn{3}{|l|}{7} & \multicolumn{3}{|l|}{8} & \multicolumn{3}{|l|}{9} \\
\hline $\begin{array}{l}t \\
(\min )\end{array}$ & $\begin{array}{l}d \\
(\mu \mathrm{m})\end{array}$ & $\begin{array}{l}\nu(\mu \mathrm{m} / \\
\mathrm{hr})\end{array}$ & $\begin{array}{l}t \\
(\min )\end{array}$ & $\begin{array}{l}d \\
(\mu \mathrm{m})\end{array}$ & $\begin{array}{l}v(\mu \mathrm{m} / \\
\mathrm{hr})\end{array}$ & $\begin{array}{l}t \\
(\min )\end{array}$ & $\begin{array}{l}d \\
(\mu \mathrm{m})\end{array}$ & $\begin{array}{l}\nu(\mu \mathrm{m} / \\
\mathrm{hr})\end{array}$ & $\begin{array}{l}t \\
(\mathrm{~min})\end{array}$ & $\begin{array}{l}d \\
(\mu \mathrm{m})\end{array}$ & $\begin{array}{l}\gamma(\mu \mathrm{m} / \\
\mathrm{hr})\end{array}$ & $\begin{array}{l}t \\
(\min )\end{array}$ & $\begin{array}{l}d \\
(\mu \mathrm{m})\end{array}$ & $\begin{array}{l}\gamma(\mu \mathrm{m} / \\
\mathrm{hr})\end{array}$ \\
\hline 43 & - & - & 3.5 & 7 & 120 & 38 & 25 & 39 & 3 & 6 & 120 & & & \\
\hline 2.5 & 8 & 192 & 100 & - & - & 143 & - & - & 24 & - & - & 21 & - & - \\
\hline 52 & - & - & 1 & 4 & 240 & 18.5 & 18 & 58 & 6.5 & 8 & 74 & 12 & 8 & 40 \\
\hline 4 & 12 & 180 & & & & & & & 7 & - & - & 52 & - & - \\
\hline 60.5 & - & - & & & & & & & 1 & 8 & 480 & 7 & 19 & 111 \\
\hline 2 & 8 & 240 & & & & & & & 65 & - & - & 31 & - & - \\
\hline 38 & - & - & & & & & & & & & & 5 & 13 & 156 \\
\hline 10.5 & 11 & 63 & & & & & & & & & & & & \\
\hline 20.5 & - & - & & & & & & & & & & & & \\
\hline 4 & 8 & 120 & & & & & & & & & & & & \\
\hline 18 & - & - & & & & & & & & & & & & \\
\hline 8 & 8 & 60 & & & & & & & & & & & & \\
\hline 33 & - & - & & & & & & & & & & & & \\
\hline 5 & 7 & 84 & & & & & & & & & & & & \\
\hline 83 & - & - & & & & & & & & & & & & \\
\hline * & * & * & & & & & & & & & & & & \\
\hline 92 & - & - & & & & & & & & & & & & \\
\hline 5 & 13 & 156 & & & & & & & & & & & & \\
\hline 15 & - & - & & & & & & & & & & & & \\
\hline 8 & 17 & 213 & & & & & & & & & & & & \\
\hline 27 & - & - & & & & & & & & & & & & \\
\hline 5 & 14 & 168 & & & & & & & & & & & & \\
\hline
\end{tabular}

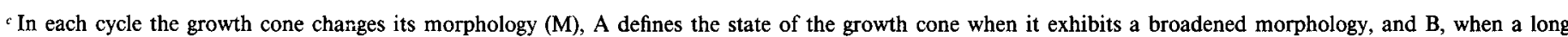
filopodium is sent out in one direction that the streamlined growth cone follows.

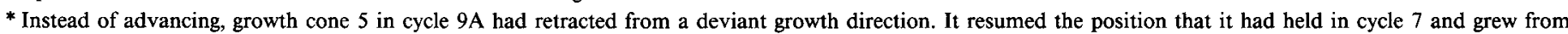
there into a forward direction.

emerged from growth cone-like features at the tips of branches or from elsewhere along the branches' extent was equal. The morphology that the arbor exhibited after $13 \mathrm{hr}$ is shown in Figure $6 b$. Unlike growth cones on advancing axons, the growth cone-like features on the branches of the arbor did not extend forward to cover significant distances. Instead, the growth cones remained more or less close to where they were seen first and moved more locally to the left and right. This was accompanied by ruffling of the growth cone membranes. At the same time, filopodia and filopodia-like branches were sent out into all directions and arose either from the veils (Fig. 5, frames 1-26) or close to the base of the branches (frames 12-24). The thin branch emerging at the right major branch (frame 12) regressed and had disappeared after $3 \mathrm{hr} 30 \mathrm{~min}$ (frame 26). A new branch emerged at a similar position (frame 30 ) but also disappeared after $45 \mathrm{~min}$ (frame 33). Although the two major branches had stretched as if they would develop into stable branches, they shrank (frames 23,24 ) and initiated a new bout of lamellipodial activity and sprouting of filopodia. Both branches directed their major growth activity to one side (to the left side in frames 25 36). During this growth, the right branch actually curved as if it grew around an obstacle. The time-lapse movies allowed us to discriminate thin and highly active lamellipodia along this curving branch, which cannot be made out in the photographs. While the left branch grew in length, ruffling of its lamellipodia continued and filopodia emerged and disappeared. The veils became smaller with time and did not reach far from the branch. Along with this apparent stabilization of the left branch the right branch pulled back from its curved route (Fig. 5, frames 3240 ), and reassembled material to form a new growth cone on its tip (frames $45-47$ ). Lead by the cone, the branch grew at a right angle to the left-hand branch. The left branch had transiently given rise to a side branch in a direction parallel to the elongating right branch (frames 45-47) but resorbed this branch entirely (frame 48). Lamellipodia and filopodia gradually slowed in their activity, although individual veils and filopodia arose here and there. At the end of the recording session, the arbor was viewed at different focal depth (see Materials and Methods) and appeared as shown in Figure $6 b$. In its morphology it closely resembled arbors previously analyzed in fixed embryo brains (Stuermer, 1988c; Stuermer et al., 1990).

Other arbors $(N=9$ : five temporal axons over rostral and four nasal axons over caudal tectal regions) were monitored over periods of $48 \mathrm{~min}$ to $10 \mathrm{hr} 30 \mathrm{~min}$. In addition to the arbor in Figure 5, three of the temporal and two of the nasal arbors were observed over their entire extent in the plane of focus and were seen to change their arborization patterns in a mode similar to the axon described above. On these six arbors, an average of $2.3(\mathrm{SD}, \pm 0.8)$ branches were extended, and $1.5(\mathrm{SD}, \pm 0.5)$ retracted. 

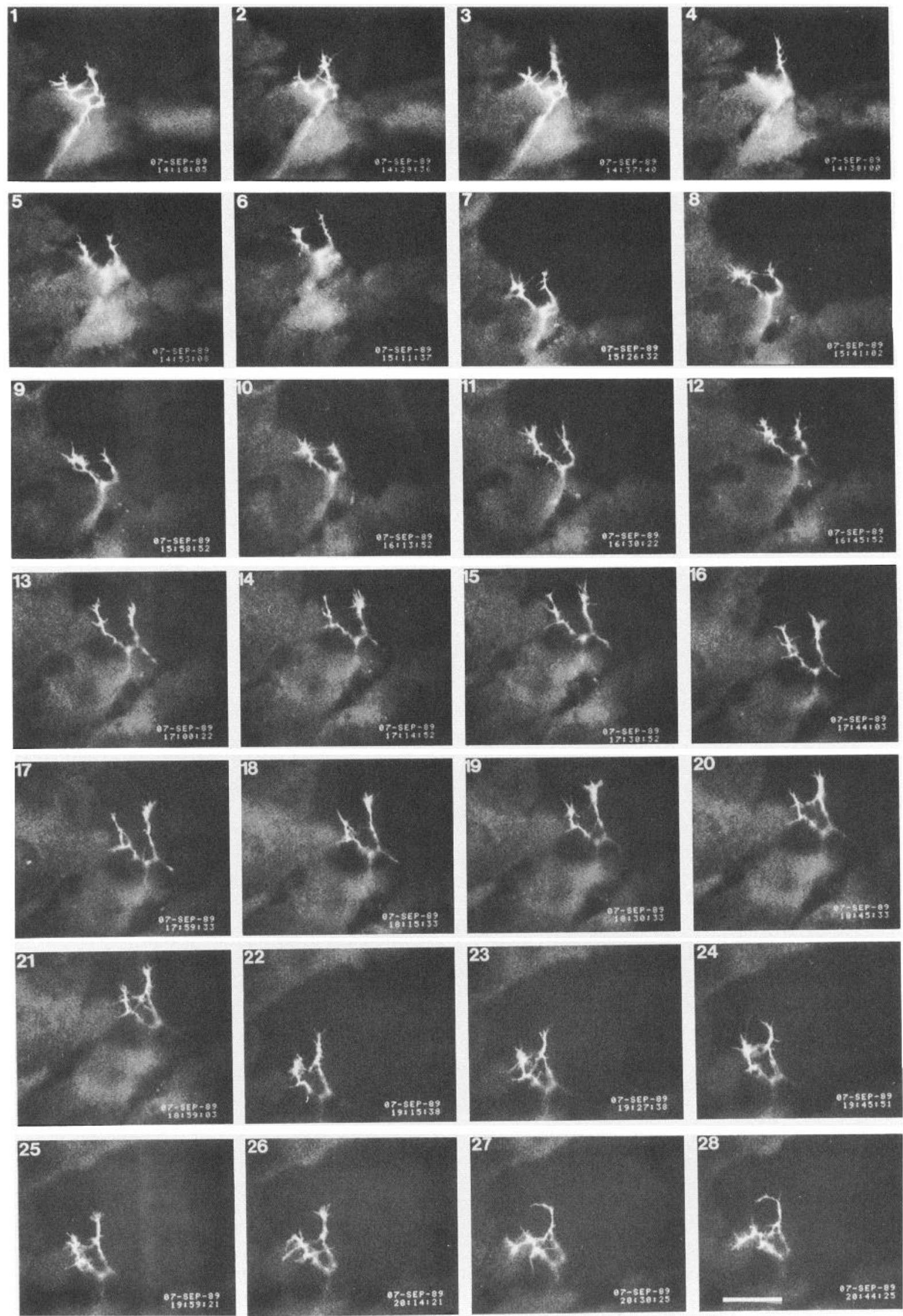

Figure 5. Series of photomicrographs (frames 1-52) from a time-lapse video documenting the elaboration of an arbor of a ventrotemporal axon in the dorsorostral tectum (compare Fig. 6). The numbers in the right-hand corner give the date and the time of the time-lapse recording, which

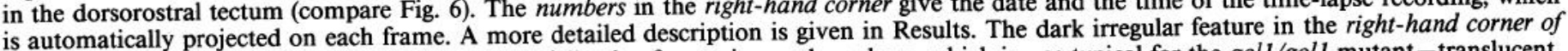
is automatically projected on each frame. A more detailed description is given in Results. The dark irregular feature 

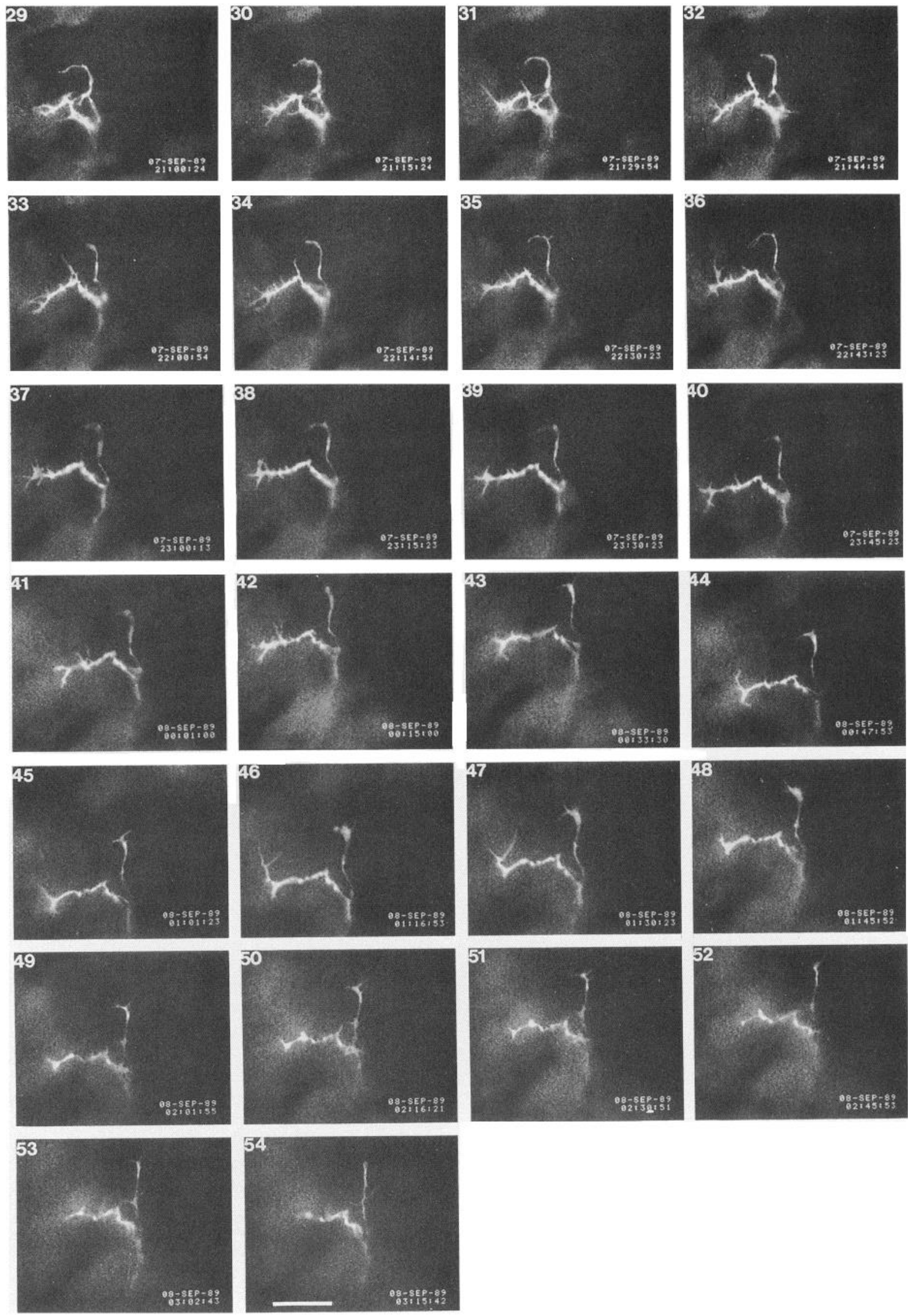

The small fluorescent dots first visible in frame 7 , and then throughout frame 14 , are within moving cells, possibly macrophages, which tend to incorporate small dye particles. Scale bars, $20 \mu \mathrm{m}$. 

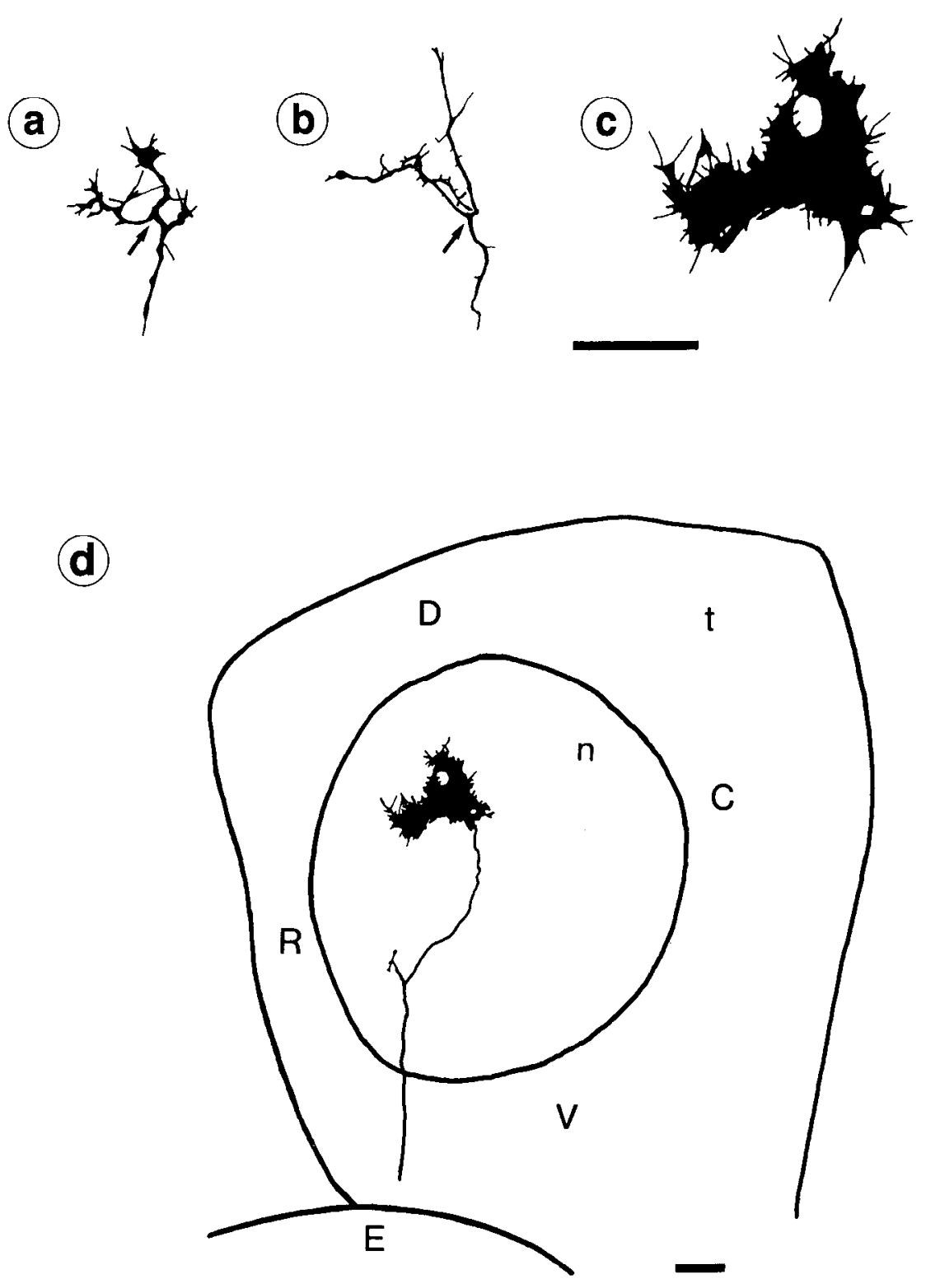

Figure 6. The small arbor from Figure 5 at the beginning of the time-lapse recording (a) and after $13 \mathrm{hr}(b)$. The $a r$ rows in $a$ and $b$ indicate the bifurcation point that is stable, while the first bifurcation point in $a$ to the right of the marked point disappears along with the retraction of the first right-hand side branch. The arbor's exploration field is shown in $c$. $d$, Outline of the tectum, the neuropil, the axonal path, and the position of the exploration field of the arbor in $a-c$. The short side process, $\sim 80 \mu \mathrm{m}$ rostral to the arbor, is probably a remnant of an carlicr bricf deviation of the growth cone from its target-directed route. Abbreviations are as in Figure 1. Scale bars, $20 \mu \mathrm{m}$.

The remaining four arbors (two temporal and two nasal arbors, not shown) were already larger at the onset of the recordings and fairly elaborated. They were only observed in parts since they did not fit into the field of view provided by the $100 \times$ lens. At lower-power magnification it was impossible to monitor the modifications on their branches. These arbors had longer branches, most of which persisted over the observation time $(3-16.5 \mathrm{hr})$, and main branches that changed only gradually in length, curvature, and number of branch points for higher-order branches. Rapid alterations of processes did occur, but they were restricted to higher-order side branches or to the tips of branches. The appearance of these four arbors resembled closely the morphology of arbors in adult fish (Stuermer, 1984, 1988c; Stuermer et al., 1990), suggesting that they were more mature than the ones described before.

Thus, when retinal growth cones have reached their retinotopic home territory, they cease to advance and begin to form terminal arbors. The development of the arbors involves the formation and retraction of primary and higher-order side branches, that is, a phase of local exploratory growth, until primary and secondary side branches are stabilized. Dynamic changes continue on higher-order side branches even on arbors that resemble in their morphology the arbors in adult fish (Stuermer, 1988c).

Exploration fields. To yield a measure for the range of exploratory growth and thus in turn for the precision of retinotopic targeting, the exploration fields of six arbors (arbors of Figs. 4 and 5 and a further three temporal and two nasal arbors that had been observed over their entire extent in the plane of focus) were set into relation to the surface area of the tectal neuropil. For one arbor, we measured exploration fields of an early and a later stage of its development (terminal arbors 1 and 6 in Table 2). The exploration fields were measured by integrating over time the tectal area that was transiently touched or permanently occupied by lamellipodia, filopodia, growth cones, and branches. The fields covered $1.0-5.3 \%$ of the tectal surface area and were 1.2-5.6 times larger than the arbors seen at the end of the observation period (Table 2). The areal value of each exploration field became larger the longer the duration of the observation time, and was the largest for the arbor that was observed over 
$13 \mathrm{hr}$. When set into relation to the tectal area covered by arbors at the end of the recording period, the fields increased in size with a rate of $29.0 \% / \mathrm{hr}(\mathrm{SD}, \pm 5.8 \% / \mathrm{hr})$. Although the area value of these exploration fields grew, there was only a slight increase in their diameter. Increase of the area value resulted from the transient occupance of spaces between and around the major branches of the arbor by processes that did not persist. The exploration field of the arbor in Figure $4 a$ is shown in Figure $4 b$, and that of the arbor in Figures 5 and 6, $a$ and $b$, in Figure $6 c$. The location and extent of the latter with respect to the tectal neuropil are shown in Figure $6 d$.

Exploration fields of axon arbors at their target sites differ in shape from fields explored by growth cones on the tips of advancing axons that travel toward and have not yet reached their retinotopic destination. Exploration fields of arbors were more circular and larger in diameter (Figs. $4 b, 6 c, d$ ). The exploration fields of advancing growth cones were elongated and correlated in their lateral extension to the diameter of the growth cones. One typical example is shown in Figure 7 . These data reflect that advancing growth cones are target directed and do not deviate much from the straight route to their targets.

Sizes of retinal axon arbors. The long and short axes of the 10 arbors that were monitored as a whole or in parts were measured and averaged scparately. Since all of these arbors changed in shape and size, they were measured twice, at the beginning and at the end of the recording period (except for the arbor in Fig. 4, which began its formation and was measured once). Among them was one arbor that was $48 \times 33 \mu \mathrm{m}$ at 83 hr PF and had grown to $93 \times 75 \mu \mathrm{m}$ by $100 \mathrm{hr}$ PF. The earlier quantification of arbors sizes (Stuermer, 1988c; Stuermer et al., 1990) had shown that arbors of these dimensions were rare. The average arbor size in these 76-106 hr PF embryos was $36 \times 27$ $\mu \mathrm{m}$. This value was compared to data of an earlier publication in which arbor sizes were determined in fixed brains of 70-100 hr PF embryos. In fixed embryos (70-100 hr PF), arbors were $31 \times 22 \mu \mathrm{m}(n=181)$ (Stuermer, 1988c; Stuermer et al., 1990); corrected for the $20 \%$ shrinkage during fixation, they were 39 $\times 28 \mu \mathrm{m}$. These values are similar to arbor sizes determined in the present study and are taken as an indication that the repeated illumination necessary for time-lapse recordings did not affect the normal development of arbor size.

\section{Discussion}

The combination of fluorescent nerve fiber tracing and videomicroscopy has allowed the direct observation of the growth of individual retinal axons in the tectum of living zebrafish em-

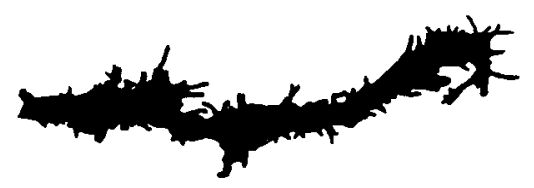

Figure 7. Typical example of an exploration field of an advancing growth cone. This field is elongated as opposed to the more circular fields of terminal arbors (compare Figs. $4 b, 6 c, d$ ). Scale bar, $20 \mu \mathrm{m}$.

bryos. Prior to the arrival at their target, growth cones, whether from nasal or temporal retinal origin, progressed through the tectum unerringly toward their retinotopic destination. The timelapse movies revealed that an individual growth cone changed its shape periodically in connection with its stop-and-go mode of traversing through the tectum. A growth cone is elongated while it advances rapidly and is broader and forms distinct lamellipodia and numerous filopodia when it pauses. The most striking and unexpected scenario of axon growth in vivo that was revealed by the videos was the formation of terminal arbors. Upon arrival at their target area, the axons began and continued over many hours to emit and retract side branches, thercby gradually shaping out their terminal arbors. Although branches arose and receded in an unpredictable and apparently random fashion, they were all restricted to a small and nearly circular territory of tectum, the "exploration field." This field comprised not more than $1-5.3 \%$ of the entire surface area of the tectal neuropil.

To visualize the growth and branching behavior of retinal axons, we used the lipophilic dyes DiI and DiO. These dyes were reported to be nontoxic in long-term multiple-exposed cultures (Honig and Hume, 1986) and did not interfere with growth per se (Honig and Hume, 1989). However, as others before us ( $\mathrm{F}$. Bonhoeffer, personal communication, in vitro), we noted that long light exposures would eventually photodamage the labeled axons, leading to their degeneration and the acquisition of a beaded appearance. The onset for such degenerative changes was unforeseeable and varied from case to case. Although it is unlikely, we cannot rule out the possibility that even some of the morphological changes that are considered here as typical growth characteristics of axons are artifacts resulting from repeated light exposures. Against this possibility speaks the fact that the growth-related features, such as growth cone advancement and terminal arbor formation, occurred in a sim-

Table 2. Sizes of terminal arbors and their exploration fields

\begin{tabular}{|c|c|c|c|c|c|c|c|}
\hline \multirow{2}{*}{$\begin{array}{l}\text { Arbor } \\
\text { number }\end{array}$} & \multicolumn{3}{|c|}{ Size $\left(\mu \mathrm{m}^{2}\right)$} & \multicolumn{2}{|c|}{$\%$ Neuropil } & \multirow{2}{*}{$\begin{array}{l}\text { EF: } \\
\text { TA }\end{array}$} & \multirow{2}{*}{$\begin{array}{l}\text { Time of } \\
\text { observation }\end{array}$} \\
\hline & $\mathrm{TA}$ & $\mathrm{EF}$ & $\mathbf{N}$ & $\mathrm{TA}$ & $\mathrm{EF}$ & & \\
\hline 1 & 190 & 230 & 22,300 & 0.85 & 1.03 & 1.2 & $0 \mathrm{hr} 48 \mathrm{~min}$ \\
\hline 2 & 150 & 380 & 18,900 & 0.79 & 2.01 & 2.5 & $5 \mathrm{hr} 30 \mathrm{~min}$ \\
\hline 3 & 250 & 810 & 20,800 & 1.20 & 3.94 & 3.2 & $6 \mathrm{hr} 30 \mathrm{~min}$ \\
\hline 4 & 260 & 960 & 18,100 & 1.44 & 5.30 & 3.7 & $7 \mathrm{hr} 50 \mathrm{~min}$ \\
\hline 5 & 240 & 760 & 19,700 & 1.22 & 3.85 & 3.2 & $10 \mathrm{hr} 30 \mathrm{~min}$ \\
\hline 6 & 180 & 610 & 22,300 & 0.81 & 2.75 & 3.4 & $12 \mathrm{hr} 30 \mathrm{~min}$ \\
\hline 7 & 140 & 780 & 19,900 & 0.70 & 3.92 & 5.6 & $13 \mathrm{hr} 05 \mathrm{~min}$ \\
\hline
\end{tabular}

EF, exploration field; N, neuropil; T $\Lambda$, terminal arbor. Sizes of terminal arbors, cxploration ficlds, and neuropil werc determined at the end of the time-lapse videorecordings (as described in Materials and Methods), from embryos of 76$93 \mathrm{hr}$ PF. 
ilar mode whether the axons had been exposed to fluorescent light only briefly or for longer time periods. Moreover, the axons had healthy-looking growth cones much like axons in vitro (Vielmetter et al., 1990) and changed their shape periodically in close correlation to their cycles of fast growth and pausing. Moreover, average growth rates of growth cones and sizes of terminal arbors in this study were in the same range as those determined in fixed embryos that had not been exposed to fluorescent light during axon growth (Stuermer, 1988c). The retractions of branches during arbor development are also unlikely to be lightinduced degenerative events because these branches did not exhibit a headed appearance and were, in contrast to photodamaged processes, actively withdrawn and reincorporated into the axoplasm.

Time-lapse recordings of growing axons in situ have been carried out in other systems (Godement and Mason, 1990; O'Connor et al., 1990; Sretavan, 1990), including retinal axons in the tectum of Xenopus (Harris et al., 1987; O'Rourke and Fraser, 1990). The growth behavior of retinotectal axons in zebrafish, however, differed considerably from that in Xenopus. Harris et al. (1987) monitored growing retinal axons in Xenopus continuously over hours and reported that axons emitted branches as soon as they had entered the tectum. Zebrafish axons, in contrast, continued to advance through the tectum with a single leading growth cone on their tips and rarely had a side branch, until they reached their retinotopic home territory. They thus grow through the tectum much as they did in the tract with the one exception that their average tectal growth rate was slower than in the tract.

The time-lapse movies of growing axons in vivo also revealed that the growth of zebrafish growth cones in the tectum is characterized by periods of rapid progression alternating with periods in which growth cones paused and enlarged. This growth mode resembles the saltatory growth of $\mathrm{PC} 12$ cell axons in vitro (Argiro et al., 1984; Aletta et al., 1986), and mouse embryonic axons in vivo (Bovolenta and Mason, 1987; Godement and Mason, 1990). One of the first accounts of this pulsatory growth may be the description of the migratory behavior of fibroblasts by Abercrombie et al. (1970). Migrating neurons in embryonic development exhibit a similar stop-and-go feature (Edmondson and Hatten, 1987). Parallel to these bouts, the growth cone underwent changes in shape from elongated during rapid progression to elaborated forms with prominent veils and multiple filopodia. The more elaborate growth cones probably explore their local environment. They send filopodia into various directions, which are sometimes followed by lamellipodial extensions. This interaction is very local and takes time, such that the growth cone hardly advances. The activity of the elaborated growth cones speaks for the inference that growth cones of this shape are in fact exploring rather than resting before taking off again. Retinofugal growth cones in mice (Bovolenta and Mason, 1987) and motor axons in chick (Tosney and Landmesser, 1985) were reported to exhibit a more complex shape at decision points of their path. Most of the filopodia and lamellipodia of the zebrafish complex growth cones are withdrawn, and only the one filopodium extended into the "preferred" direction is quite rapidly followed by the entire growth cone. Thus, the rapid advancement and acquisition of a streamlined form can be interpreted as the reaction of the growth cone to having found its "preferred" direction.

That axons have indeed a "preferred direction" is supported by the observation that the growth cones almost always moved into the direction of the retinotopic target. Brief deviations from this route appear to be corrected by withdrawal of the growth cone from the inappropriate direction followed by progression with the "correct" orientation. Occasional short and thin side branches, such as the one seen in Figure 6, at considerable distance from the highly branched terminal arbor have been observed in previous analyses on retinal axon arbors (Stuermer, 1984, 1988c; Stuermer and Raymond, 1989). From the present in vivo observations, we conclude that such side branches are the remaining trace of a growth cone's transient detour. However, since time-lapse recordings are made on a small sample of individual axons, it remains uncertain whether this applies to all such side branches.

Such a growth mode is consistent with the idea that the growth cones read directional cues on the tectum that guide them to their retinotopic destination. In both Xenopus (Holt and Harris, 1983) and zebrafish embryos (Stuermer, 1988c), dorsal and ventral retinal axons select their retinotopically appropriate tectal halves right upon ingrowth into the tectum. Nasal and temporal arbors are in Xenopus (stage 45/46), however, coextensive with a subtle bias of branching (O'Rourke and Fraser, 1990). With repeated observations of individual axons in daily intervals, O'Rourke and Fraser (1990) demonstrated that a clear topography along the rostrocaudal axis of the Xenopus tectum evolves gradually through shaping of the overlapping arbors. The behavior of embryonic axons in the zebrafish tectum differs from that of temporal and nasal axons in Xenopus in that axons continue to grow and arborize only when they have reached an area of tectum that correlates topographically to their retinal origin. Thus, arbors of nasal and temporal axons are in zebrafish, always and even in the process of formation, clearly restricted to a small area in the caudal and rostral tectum, respectively. In earlier stages, before the retinal axons have reached their retinotopic target sites, the temporal and nasal axons in zebrafish are coextensive over the rostral tectal half (Stuermer, 1988c). However, the nasal axons do not arborize in rostral tectum. This result from our previous studies was confirmed by the present result on live axons. Instead, nasal axons were seen to form their terminal arbors only after they had reached the caudal tectum, and only at their retinotopically appropriate domains within the caudal tectum.

The selectivity of the nasal axons for growing into the caudal tectum and producing their terminal arbors at retinotopic sites was even more obvious in earlier experiments, in which the temporal retina had been ablated prior to the arrival of the axons in the tectum (Stuermer, 1988c). In these instances, the nasal axons crossed the "vacant" rostral tectum and passed into their caudal tectal home territories to develop their terminal arbors in small retinotopically appropriate locations. It is surprising that retinal axons in fish during axonal regeneration behave in a very different way. They enter and grow over the tectum in abnormal paths and branch initially widely (Schmidt et al., 1988; Stuermer, 1988a,b). Over periods of months, they loose branches from ectopic sites and acquire routes that in their final portions are target directed and form terminal arbors of normal size and morphology over retinotopic target sites. The fact that regenerating axons manage to find their retinotopic targets from any abnormal position suggests that the gradients of tectal markers are still available to the axons (Gierer, 1987). In fact, the presence and function of one of these marker molecules (the repellent guidance component of the caudal tectum) have been demonstrated directly in the so-called in vitro stripe assay (Viel- 
metter and Stuermer, 1989). The extensive branching of regenerating axons in the tectum of adult fish may result from both, from gradients that are shallower in the larger adult tectum and from the abnormal routes through which the regenerating axons enter into the tectum (Stuermer, 1988a,b).

Xenopus arbors are large from the beginning, covering most of the tectum, and do not alter significantly in their rostrocaudal extent during the shaping.process (O'Rourke and Fraser, 1990). The area of tectum that they cover, however, becomes smaller with time, since the tectum enlarges and does so more rapidly than the subsequent slow growth of the arbors (Sakaguchi and Murphey, 1985). Zebrafish arbors grow larger during the time between the formation of the first bifurcation and the subsequent branch additions (and retractions). They continue to grow into adulthood (Stuermer, 1988c). However, the arbor sizes are from the start small (with $27 \times 36 \mu \mathrm{m}$ on average in a tectum of 180 $\times 200 \mu \mathrm{m}$ ) and remain small, despite their growth, with respect to the size of the tectal neuropil (Stuermer, 1988c).

Although Xenopus and zebrafish differ as to where the axons begin to arborize, they have in common that the developing arbors modify their appearance and branching pattern by branch addition and retraction. Determining whether the rapidity of branch emission and retraction is in Xenopus as high as in zebrafish would require the performance of time-lapse recordings in Xenopus of a higher temporal resolution.

Branches evolve from growth cone-like features on arbors or, as in Xenopus (Harris et al., 1987), as "thin worm-like processes" without growth cones and by forward and back-branching. In zebrafish, arbors develop over a small and retinotopic field of tectum, which is in clear contrast to arbor development in the tectum of Xenopus and some other species (Nakamura and O'Leary, 1989; Simon and O'Leary, 1990). The reasons for this difference in zebrafish and Xenopus retinotectal development are unknown. Zebrafish appear to possess a clear difference between the rostral and caudal tectal half when the axons invade, as suggested by the fact that each axon grows to its specific home before it arborizes. The positional specification along the rostrocaudal axis of developing Xenopus tecta may be less distinct by the time the axons arrive, and probably develops with the addition of new tectal territory.

\section{Comparison with the gradient model}

Zebrafish axons show a behavior that was predicted under the premise that axons grow under the influence of tectal positional markers that are distributed over the tectal axes in gradients (Gierer, 1987).

It is widely believed that the tectum provides a set of positional markers for the guidance of retinal axons to their retinotopic home (Attardi and Sperry, 1963; Sperry, 1963; Bonhoeffer and Gierer, 1984), and a number of experimental evidences (Bonhoeffer and Huf, 1985; Walter et al., 1987) support the notion that such markers are distributed in a graded fashion over the axes of the tectum (Gierer, 1981, 1987). Since the growth and branching behavior of zebrafish axons fits perfectly the predictions of the Gierer $(1981,1987)$ model, it appears useful to reiterate the major issues here.

The guiding effects of the positional markers depend on the steepness of the concentration gradient of the molecules involved, and on the ability of the growth cone to amplify subtle concentration differences (Gierer, 1987). According to Gierer (1987), a growth cone would cease to advance at a tectal position where the combination of markers is optimal for the individual growth cone. Approaching that position, the slope of the combined effect of the marker gradients becomes more and more shallow and is zero in the "optimal" position. The optimal position is surrounded by an area in which the growth cone is not able to discriminate the marker combinations on the tectal cells because the gradient is too shallow. A growth cone reaching such an area no longer has a preferred growth direction and starts branching, and such a behavior is seen here for zebrafish axons. The exploration field of a developing zebrafish arbor could be identical to such a tectal area in which the marker combination is roughly optimal and the steepness of the gradients is below a threshold for the growth cone's measuring system. Moreover, this area, that is, the exploration field, was small and thus in turn provides a clue as to how precisely the retinotopic home can be discriminated from neighboring regions.

\section{Exploratory growth}

We have used the term "exploration field" to imply that the axons may within retinotopic areal constraints "probe" their local environment in a trial-and-error mode. It is known that retinal axons form synapses with various profiles and in particular with dendrites part of which arise from tectal neurons in the deep tectal layer stratum periventriculare (Meek, 1983; Stuermer and Easter, 1984). In adult fish as well as already in young larvae, retinal axon arbors are layered within the stratum fibrosum et griseum superficiale (SFGS) (Springer and Gaffney, 1981; Stuermer, 1984; Schmidt et al., 1988; Stuermer and Raymond, 1989). In frogs, different layers have axons with functionally different response properties to stimuli onto the retina (Maturana et al., 1960). An idea that remains to be tested is that fish axon arbors from ganglion cells with different response properties, such as for instance "on" and "off" cells (Jacobsen and Gaze, 1964), perform their exploratory growth to probc the dendrites in search for their appropriate layer and postsynaptic partner.

We are only observing one axon at a given time. While the labeled axon under observation develops its arbor, a number of arbors for similar retinotopic sites are elaborated and remain unseen. It is therefore likewise possible that branches of different axons meet and interact with one another and that the selection of certain branches and retraction of others by an individual arbor are influenced by the interaction with its neighbors. The pruning of arbors and the formation of precisely organized neural interconnections have in many systems been demonstrated to require activity-mediated axon-target communication (Sretavan et al., 1988; Cline and Constantine-Paton, 1989; Nakamura et al., 1990). We have not found an influence of blocking the Na channel-dependent spike activity with TTX on arbor size and arbor position in zebrafish (Stuermer et al., 1990). A speculation derived from the above considerations is that perhaps the selection of the appropriate layer of SFGS and the selection of the appropriate synaptic partner by zebrafish arbors during their exploratory growth may require neural activity.

For the purpose of monitoring the development of terminal arbors in live animals, the distribution and orientation of the retinal axon arbors in fish and amphibians are of great advantage. The arbors are by and large expanded horizontally and almost parallel to the tectal surface. Fish retinal arbors are layered, as stated above, and each arbor has a very limited width in the radial dimension of the tectum (Stuermer, 1984; Schmidt et al., 1988). This enabled us to view in the best cases the arbors in a given focal plane throughout most of their extent. However, 
while keeping the arbor's most active processes in planar focus, we may have missed potential dynamical changes of arbor processes deep to the plane of observation. Since arbor growth, however, occurs predominantly in the plane parallel to the surface, we are confident that we were able to visualize most of its characteristic growth-related changes.

Since fish tecta, like those in Xenopus, continue to grow and grow caudally more than rostrally, a gradual transposition (i.e., shifting) of arbors for most into the caudal direction is required (Constantine-Paton et al., 1983; Frascr, 1983; Easter and Stuermer, 1984). Seeing the modifications of arbors in this timelapse study helps to envision how shifting may actually occur. In particular, our time-lapse recordings included arbors that were already fairly elaborated and large when we detected and began to film them. Unlike the small and newly developing arbors, these larger arbors appeared more stable and exhibited a rapid turnover of processes only at the tips of branches. Shifting may, whether in adult fish or juvenile frogs, correspond with alterations similar to the ones seen on the larger and more mature-appearing arbors in this study (Constantine-Paton et al., 1983; Easter and Stuermer, 1983; O'Rourke and Fraser, 1990). In other words, the tips of the branches may retain the ability to "search" for new synaptic partners and to stabilize processes in the direction in which shifting occurs, for rostral arbors, for instance, predominantly into the caudal direction. Concurrently, processes or branchcs oppositc from the direction into which the shift occurs are withdrawn, much like during the event of branch retraction illustrated in Figures 4 and $5, a$ and $b$. While shifting in small and rapidly growing fish may be fast and potentially visible with long-duration time-lapse recordings over a day or so, the modifications of arbors in adults may be more subtle, slower, and certainly more difficult to visualize in live animals.

In other reports, individual axonal and dendritic arborizations were visualized several times in intervals of days and months and demonstrated morphological changes over time occurring in young and adult animals. Repeated in vivo observations showed morphological changes on dendritic arbors in superior cervical ganglion neurons of young and adult rodents (Purves and Hadley, 1985; Purves et al., 1986; Voyvodic, 1987) and of single neuromuscular junctions of the adult frog Rana pipiens (IIerrera and Werle, 1990; IIerrera et al., 1990). These findings and more of a similar kind (Lichtman et al., 1985; Rich and I ichtman, 1989; Wigston, 1989, 1990) underscore the generality of arbor remodeling during regeneration, development and in adults. Such remodeling as well as shifting of terminal arbors involves breakage and formation of new synapses. For the developing arbors in zebrafish embryos, we do not yet know whether the axons have formed synapses or not, but it will be interesting to investigate whether branch turnover in embryogenesis would concur with a rapid turnover of synapses.

\section{References}

Abercrombie M, Heaysman JEM, Pegrum SM (1970) The locomotion of fibroblasts in culture. Exp Cell Res 59:393-398.

Aletla JM, Greene LA, Edmondson JC (1986) Cytological features observed during NGF-dependent neurite elongation and growth cone motility in PC12 cells. Soc Neurosci Abstr 12:368.

Argiro V, Bunge MB, Johnson MI (1984) Correlation between growth cone form and movement and their dependence on neuronal age. $J$ Neurosci 4:3051-3062.

Attardi DG, Sperry RW (1963) Preferential selection of central pathways by regenerating optic fibers. Exp Neurol 7:46-64.
Bonhoeffer F, Gierer A (1984) How do retinal axons find their targets on the tectum. Trends Neurosci 7:378-381.

Bonhoeffer F, Huf J (1985) Position-dependent properties of retinal axons and their growth cones. Nature 315:409-410.

Bovolenta P, Mason C (1987) Growth cone morphology varies with position in the developing mouse visual pathway from retina to first targets. J Neurosci 7:1447-1460.

Cline HT, Constantine-Paton M (1989) NMDA receptor antagonists disrupt the retinotectal topographic map. Neuron 3:413-426.

Constantine-Paton M, Pitts EC, Reh TA (1983) The relationship between retinal axon ingrowth, terminal morphology, and terminal patterning in the optic tectum of the frog. J Comp Ncurol 218:297-313.

Crossland WJ, Cowan WM, Rogers LA (1975) Studies on the development of the chick optic tectum: IV. An autoradiographic study of the development of retinotectal connections. Brain Res 91:1-23.

Easter SS Jr, Stuermer CAO (1984) An evaluation of the hypothesis of shifting terminals in goldfish optic tectum. J Neurosci 4:10521063.

Edmondson JC, Hatten ME (1987) Glial guided granule neuron migration in vitro: a high resolution time-lapse video microscopic study. J Neurosci 7:1928-1934.

Fraser SE (1983) Fiber optic mapping of the xenopus visual system: shift of the retinotectal projection during development. Dev Biol 95: 505-511.

Fujisawa H, Tani N, Watanabe K, Ibata Y (1982) Branching of regenerating retinal axons and preferential selection of appropriate branches for specific neuronal connections in the newt. Dev Biol 90: 43-57.

Gaze RM (1970) A study of the retinotectal projection during regeneration of the optic nerve. Proc R Soc Lond [Biol] 157:420-448.

Gierer A (1981) Development of projections between areas of the nervous system. Biol Cybern 42:69-78.

Gierer A (1987) Directional cues for growing axons forming the retinotectal projection. Development 101:479-489.

Godement P, Mason CA (1990) Behavior of live retinal axon growth cones in the optic chiasm. Soc Neurosci Abstr 16:1125.

Harris WA, Holt CE, Bonhoeffer F (1987) Retinal axons with and without their somata, growing to and arborizing in the tectum of Xenopus embryos: a time-lapse video study of single fibres in vivo. Development 101:123-133.

Herrera AA, Werle MJ (1990) Mechanisms of elimination, remodeling, and competition at frog neuromuscular junctions. J Neurobiol 21:73-98.

Herrera AA, Banner LR, Nagaya N (1990) Repeated, in vivo observations of frog neuromuscular junctions: remodelling involves concurrent growth and retraction. J Neurocytol 19:85-99.

Holt CE, Harris WA (1983) Order in the initial retinotectal map in Xenopus: a new technique for labelling growing nerve fibres. Nature 301:150-152.

Honig MG, Hume RI (1986) Fluorescent carbocyanine dyes allow living neurons of identified origin to be studied in long-term cultures. J Cell Biol 103:171-187.

Honig MG, Hume RI (1989) DiI and DiO: versatile fluorescent dyes for neuronal labelling and pathway tracing. Trends Neurosci 12:333341 .

Jacobson M, Gaze RM (1964) Types of visual response from single units in the optic tectum and optic nerve of the goldfish. Q J Exp Physiol 49:199-209.

Kaethner RJ, Stuermer CAO (1990) Dynamics of axonal growth and arbor formation during development of the retinotectal projection in zebrafish embryos. Soc Neurosci Abstr 16:310.

Lichtman JW, Wilkinson RS, Rich MM (1985) Multiple innervation of tonic endplates revealed by activity-dependent uptake of fluorescent probes. Nature 314:357-359.

Maturana HR, Lettvin JY, McCulloch WS, Pitts WH (1960) Anatomy and physiology of vision in the frog (Rana pipiens). J Gen Physiol 43:129-175.

Meek J (1983) Functional anatomy of the tectum mesencephali of the goldfish. An explorative analysis of the functional implications of the laminar structural organization of the tectum. Brain Res Rev 6:247297.

Nakamura H, O'Leary DDM (1989) Inaccuracies in initial growth and arborization of chick retinotectal axons followed by course corrections and axon remodeling to develop topographic order. J Neurosci 9: 3776-3795. 
Nakamura H, Ichijo H, Kobayashi T (1990) Differentiation of avian retinotectal projection. Neurosci Res [Suppl 13] 8:S18-S23.

O'Connor TP, Duerr JS, Bentley D (1990) Pioneer growth cone steering decisions mediated by single filopodial contacts in situ. J Ncurosci 10:3935-3946.

O'Rourke NA, Fraser SE (1986) Dynamic aspects of retinotectal map formation revealed by a vital-dye-tracing technique. Dev Biol 114: $265-276$.

O'Rourke NA, Fraser SE (1990) Dynamic changes in optic fiber terminal arbors lead to retinotopic map formation: an in vivo confocal microscopic study. Neuron 5:159-171.

Purves D, Hadley RD (1985) Changes in dendritic branching of adult mammalian neurones revealed by repeated imaging in situ. Nature 315:404-406.

Purves D, Hadley RD, Voyvodic JT (1986) Dynamic changes in the dendritic geometry of individual neurons visualized over periods of up to three month in the superior cervical ganglion of living mice. $J$ Neurosci 6:1051-1060.

Rich MM, Lichtman JW (1989) In vivo visualization of pre- and postsynaptic changes during synapse elimination in reinnervated mouse muscle. J Neurosci 9:1781-1805.

Sakaguchi DS, Murphey RK (1985) Map formation in the developing Xenopus retinotectal system: an examination of ganglion cell terminal arborizations. J Neurosci 5:3228-3245.

Scalia F, Matsumoto DE (1985) The morphology of growth cones of regenerating optic nerve axons. I Comp Neurol 231:323-338.

Schmidt JT, Turcotte JC, Buzzard M, Tieman DG (1988) Staining of regenerated optic arbors in goldfish tectum: progressive changes in immature arbors and a comparison of mature regenerated arbors with normal arbors. J Comp Neurol 269:565-591.

Simon DK, O'Leary DDM (1990) Limited topographic specificity in the targeting and branching of mammalian retinal axons. Dev Biol 137:125-134.

Sperry RW (1963) Chemoaffinity in the orderly growth of nerve fiber patterns and connections. Proc Natl Acad Sci USA 50:703-710.

Springer AD, Gaffney JS (1981) Retinal projections in the goldfish: a study using cobaltous-lysine. J Comp Neurol 203:401-424.

Sretavan DW (1990) Axon navigation at the mammalian optic chiasm: direct observation using fluorescent time-lapse video microscopy. Soc Neurosci Abstr 16:1126

Sretavan DW, Shatz CJ (1986) Prenatal development of retinal ganglion cell axons: segregation into eye-specific layers within the cat's lateral geniculate nucleus. J Neurosci 6:234-251.

Sretavan DW, Shatz CJ, Stryker MP (1988) Modification of retinal ganglion cell axon morphology by prenatal infusion of tetrodotoxin. Nature 336:468-471.

Stone J, Dreher B, Rapaport DH, eds (1984) Development of visual pathways in mammals. New York: Liss.

Stuermer CAO (1984) Rules for retinotectal terminal arborizations in the goldfish optic tectum: a whole-mount study. J Comp Neurol 229: 214-232.

Stuermer CAO (1988a) Trajectories of regenerating retinal axons in the goldfish tectum: I. A comparison of normal and regenerated axons at late regeneration stages. J Comp Neurol 267:55-68.

Stuermer CAO (1988b) Trajectories of regenerating retinal axons in the goldfish tectum: II. Exploratory branches and growth cones on axons at early regeneration stages. J Comp Neurol 267:69-91.

Stuermer CAO (1988c) Retinotopic organization of the developing retinotectal projection in the zebrafish embryo. J Neurosci 8:45134530.

Stuermer CAO, Easter SS Jr (1984) A comparison of the normal and regenerated retinotectal pathways of goldfish. J Comp Neurol 223 $57-76$.

Stuermer CAO, Raymond PA (1989) Developing retinotectal projection in larval goldfish. J Comp Neurol 28 1:630-640.

Stuermer CAO, Rohrer B, Münz H (1990) Development of the retinotectal projection in zebrafish embryos under TTX-induced neuralimpulse blockade. J Neurosci 10:3615-3626.

Tosney KW, Landmesser LT (1985) Growth cone morphology and the trajectory in the lumbosacral region of the chick embryo. J Neurosci 5:2345-2358.

Vielmetter J, Stuermer CAO (1989) Goldfish retinal axons respond to position-specific properties of tectal cell membranes in vitro. Neuron 2:1331-1339.

Vielmetter J, Stolze B, Bonhoeffer F, Stuermer CAO (1990) In vitro assay to test differential substrate affinities of growing axons and migratory cells. Exp Brain Res 81:283-287.

Voyvodic JT (1987) Development and regulation of dendrites in the rat superior cervical ganglion. J Neurosci 7:904-912.

Walter J, Kern-Veits B, Huf J, Stolze B, Bonhoeffer F (1987) Recognition of position-specific properties of tectal cell membranes by retinal axons in vitro. Development 101:685-696.

Wigston DJ (1989) Remodeling of neuromuscular junction in adult mouse soleus. J Neurosci 9:639-647.

Wigston DJ (1990) Repeated in vivo visualization of neuromuscular junctions in adult mouse lateral gastrocnemius. J Neurosci 10:17531761. 